\title{
Sistematizar coyuntura y politizar los movimientos sociales ${ }^{*}$
}

\author{
Jesús Evodio López
}

Coyuntura. Cuestiones teóricas y politicas da continuidad al trabajo crítico-marxista de Jaime Osorio. La peculiaridad de este libro reside en su planteamiento: sistematizar coyuntura, el nivel de análisis más descuidado de la teoría marxista. Pues, aunque existen monografías que abordan los términos y nociones, los conocimientos se encuentran dispersos y poco sistematizados. Estas abstracciones no permiten concretar lo que sería una herramienta fundamental para orientar la toma de decisiones en el accionar político de los diversos movimientos sociales, de ahí la importancia y necesidad de precisar una base teórica de coyuntura.

Vale la pena destacar que el libro no sólo se dirige a un lector netamente investigador o docente, sino también a cualquier persona interesada en el acontecer político, desde jóvenes estudiantes, activistas sociales, hasta dirigentes políticos. Cada apartado de este trabajo cumple con un objetivo pedagógico: la aproximación a los conceptos y conocimientos necesarios de la teoría marxista; los temas relevantes previos al estudio de coyuntura; el estudio de coyuntura; y los debates estratégicos para la aplicación sistemática de coyuntura.

La idea de conocimiento está determinada por la percepción que tenemos de la realidad. El empirismo propone que la realidad social puede conocerse mediante la observación. Este planteamiento es cierto pero limitado, y Osorio lo denomina ingenuidad empirista, porque se asume que la realidad está lista para ser conocida con la simple observación, sin mayor esfuerzo, sólo describiendo lo que se ve. Por el contrario, todo lo real siempre se nos presenta de manera distorsionada y requiere un nivel de análisis mayor: además de observar es importante teorizar, y tener en cuenta que hay procesos que permanecen ocultos.

* Reseña del libro de Jaime Osorio, Coyuntura. Cuestiones teóricas y políticas, UAMXochimilco/Itaca, Ciudad de México, 2019. 
Antes se explotaba y dominaba sin tener que ocultar procesos; en el feudalismo, por ejemplo, el siervo sabía que era siervo y el señor feudal no tenía que encubrir su poder, el cual podía ejercer explícitamente. Ahora, en el capitalismo, existe un doble proceso, ocultar las verdaderas relaciones sociales y crear una nueva realidad social. Nos movemos en un mundo de ficciones (nuestra cotidianidad), que reproducimos voluntariamente porque no son perceptibles. ¿Por qué no son perceptibles?, porque también sufrimos una violencia institucionalizada que permite encubrirlas en el orden social imperante. Una forma de romper con las distorsiones que nos impone la realidad social es entablar su estudio con teoría y cuerpos epistémicos concretos, sólo a partir de interpretaciones que vayan más allá de lo inmediato podremos distinguir y comprender lo oculto en lo visible.

El conocimiento de la realidad social se encuentra ante el desafío de la fragmentación. Al intentar estudiar la unidad más pequeña, en el caso de las ciencias sociales, el individuo, se comete el error de fraccionar lo social. Ningún individuo se puede describir por sí solo, ya que forma parte de un contexto y es la interacción con su entorno lo que determina sus decisiones. Así, si se quieren entender las razones que llevan a los individuos a decidir y actuar de tal forma, se debe partir desde sus relaciones sociales y no desde un vacío social en el que se da por sentado que cualquier decisión es válida para el individuo: ser pobre, ser rico. Si bien es complejo conocer todo, es necesario conocer el todo, tener noción de que existe una totalidad del fragmento social que se analiza.

Desde esta premisa, es la lógica del capital la que unifica nuestra vida social. No, no es la única, pero es la que predomina. En minoría, resisten las comunidades indígenas, y otras, con sus prácticas sociales alternativas a esta lógica. ¿Cómo cambiar, cómo luchar contra esta fuerza imperante?, son los periodos de convulsión social los que permiten hacer visible la disputa social, el enfrentamiento entre clases sociales. La ebullición social potencia el caos, desorganiza el orden establecido. Y es, en esa coyuntura de las crisis, donde se hace más transparente y define mejor el contorno de los sujetos sociales, de la realidad social.

Aquí es donde se destaca la importancia de la teoría marxista, sus niveles de abstracción y concreción enriquecen el análisis para aproximar el conocimiento a la realidad social desde muy diversas dimensiones:

- Modo de producción capitalista

- Sistema mundial capitalista

- División internacional del trabajo

- Intercambio desigual 
- Formas de capitalismo

- Capitalismo desarrollado e imperialista

- Capitalismo dependiente ${ }^{2}$

- Patrones de reproducción de capital

- Formación económico-social

- Coyuntura

La teoría marxista, es una teoría para la acción y, desde esta perspectiva, cada uno de los diferentes niveles, incluido coyuntura, convergen hacia la praxis.

La primera consideración es el capitalismo en sí, el sistema que organiza nuestra vida bajo la lógica del capital. Tener presente que las diversas crisis que se padecen en este sistema también son una oportunidad para emprender acciones que posibiliten la liberación de las clases oprimidas, pero, para que esto ocurra, es indispensable contar con una base teórico-política que permita guiar las decisiones y el curso de los movimientos sociales.

De la misma forma, se deben tener presente las "clases sociales" que existen en el capitalismo.

- Las facciones de clase: burguesía, terrateniente, proletariado, campesinado y pequeña burguesía.

- Sectores de clase: implica la magnitud de los medios de producción que tienen en tres niveles, grande, mediano y pequeño.

- Estamentos: religiosas, militares y demás agrupaciones institucionales cuya significación política repercute en el sistema capitalista.

- Otros agrupamientos relevantes: la resistencia de los pueblos originarios y los movimientos feministas.

Se llama lucha de clases al enfrentamiento abierto o encubierto, comúnmente entre clases antagónicas. La relación antológica estará determinada por las relaciones sociales de poder político y económico. Los oprimidos contra los opresores. Aunque, en este enfrentamiento, también intervine el proceso histórico que lleva a cada una de las clases al posicionamiento que actualmente ocupa. En este sentido y a manera de ejemplo, el proletariado cuenta con una voluntad histórica de transformación distintiva entre las demás clases dominadas.

El Estado capitalista no es una cosa aislada en sí misma, sino el conjunto de las relaciones sociales. Dado que estas relaciones no tienen como objetivo central

2 Para más detalles en el tema, véase Jaime Osorio, Teoría marxista de la dependencia: historia, fundamentos, debates y contribuciones, UAM Xochimilco/Itaca, Ciudad de México, 2019. 
la explotación o apropiación del plusvalor, se le llaman relaciones de opresión. Se llaman así porque todas las formas de poder se condensan en el Estado, aunque en diferentes pesos y grados de relevancia (jerarquía). Por lo tanto, hablar del Estado y del poder político, no es una cosa insignificante. Cuando se define a una sociedad como capitalista se señala que la clase poseedora del capital, la burguesía, también cuenta con el poder político y económico que le permite organizar la vida en común conforme a sus proyectos e intereses.

Coyuntura es el nivel de análisis de la teoría marxista donde se requiere mayor concreción, pues es la síntesis de todos los niveles que le preceden y esto significa que es en este nivel donde la potencia de la fuerza humana transformadora alcanza su mayor expresión. La revolución contra el capital es posible y necesaria, pero ello reclama la acción consciente de los explotados, oprimidos y dominados. Sólo en la coyuntura es posible intervenir en aquellas crisis y contradicciones del sistema y convertirlas en procesos liberadores. Es en la coyuntura donde la teoría se hace praxis.

Hay tres ejes generales a considerar, importantes para el estudio de coyuntura y la praxis:

- Las fuerzas internacionales: países con peso económico y geopolítico; disputas políticas y económicas entre Estados; formación económico-social a escala internacional y regional; entre otras.

- Las clases dominantes: fracturas de poder, crisis, debilitamiento de la hegemonía, desintegración política, entre otras.

- Las clases dominadas: composición, nivel de organización, fuerza social, demandas planteadas, alianzas políticas, entre otras.

Se reitera que es necesario asumir el estudio de cada apartado como un proceso reflexivo que considere a la totalidad, que no se pierda de vista la parte epistémica y teórica plateada previamente.

Este libro concluye con un breve apartado de discusiones en torno a las revoluciones políticas. Para derrocar al capitalismo, las clases dominadas tienen que definir una estrategia que integre las acciones y objetivos a alcanzar; no se debe dejar de lado la organización política, ya que es fundamental para que las luchas dispersas, demandas e intereses, de los diversos sectores y movimientos sociales puedan articularse en una sola fuerza, ésta se movilice, presione y fracture los cimientos del dominio imperante; se debe tener la capacidad de crear coyunturas y de actuar en coyunturas.

Las crisis del capitalismo en términos económicos no generan nada distinto al capital, son orgánicas a él. Por esto, su derrota no se producirá por simples crisis económicas, sino por acciones políticas que pongan fin a las relaciones sociales que lo mantienen y reproducen. Imaginar que se puede cambiar el 
orden imperante esquivando el poder político es erróneo, porque supone un triunfo que deja de lado los planes de acción que permitan llevar a cabo la nueva organización. La victoria sólo se convertirá en una resistencia temporal. Por eso se habla de crear otro poder político radicalmente distinto, que prevalezca y permita a los agrupamientos, que ahora tomarán el poder, organizar la vida en común sobre otras bases, con el propósito de arrancar todo aquello que produce el dominio y la explotación de la clase obrera. 



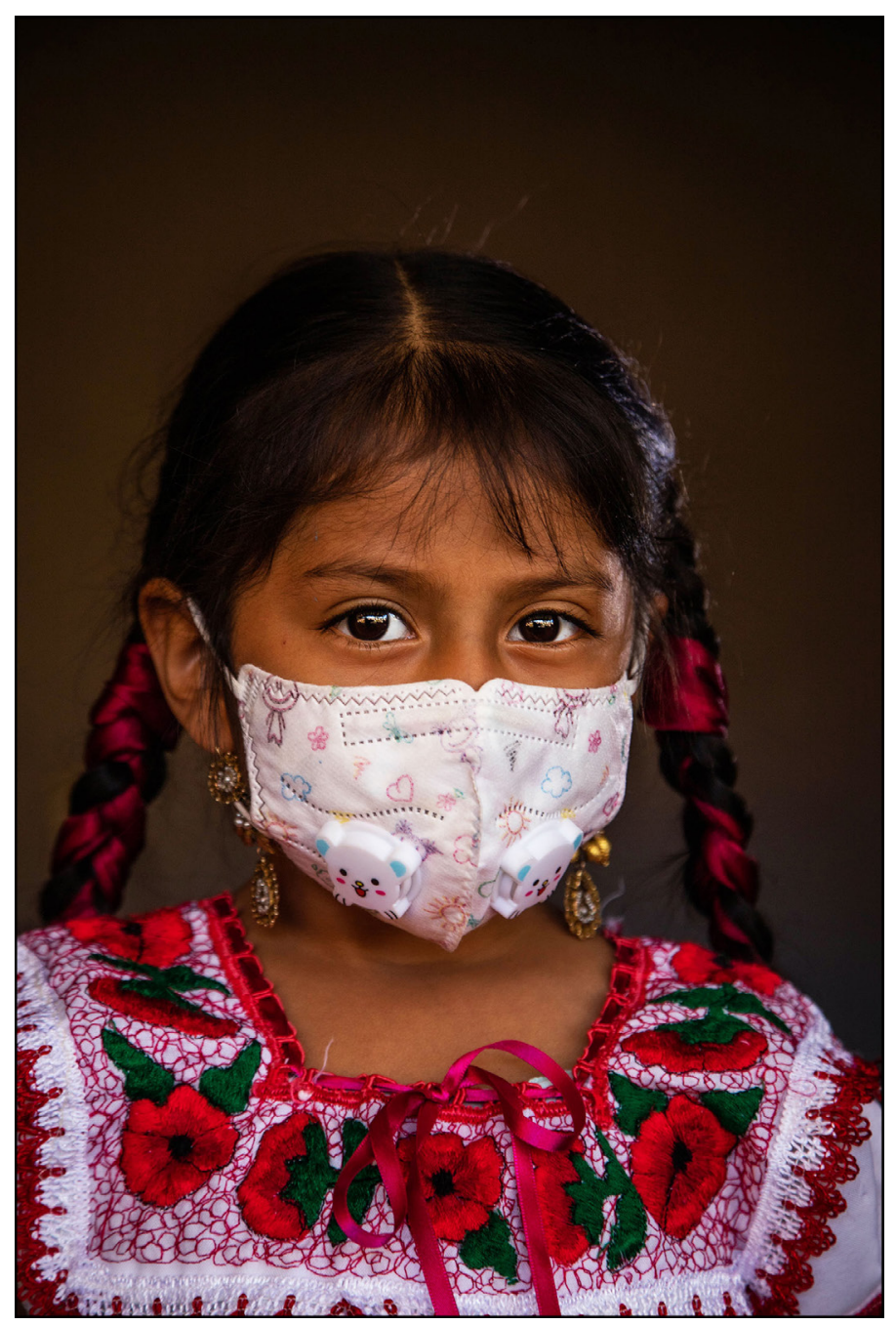


Juan Carlos Reyes García | Zulema 